\title{
Hydrogen Bond Interactions in Liquid and Supercritical Hydrofluorocarbons
}

\author{
Andrew P. Abbott*, Stuart Corr ${ }^{\#}$, Nicola E. Durling, Eric G. Hope \\ Chemistry Department, University of Leicester, Leicester, LE1 7RH, UK \\ \# Ineos Fluor, Runcorn Technical Centre, The Heath, Runcorn, Cheshire, WA7 4QD
}

E.mail andrew.abbott@le.ac.uk,

\section{Supplementary Information}

Figure 1(supp): Plot of measured absorbance maximum in $\mathrm{kK}$ against fitted value obtained using Equation 2 and the parameters in Table 1

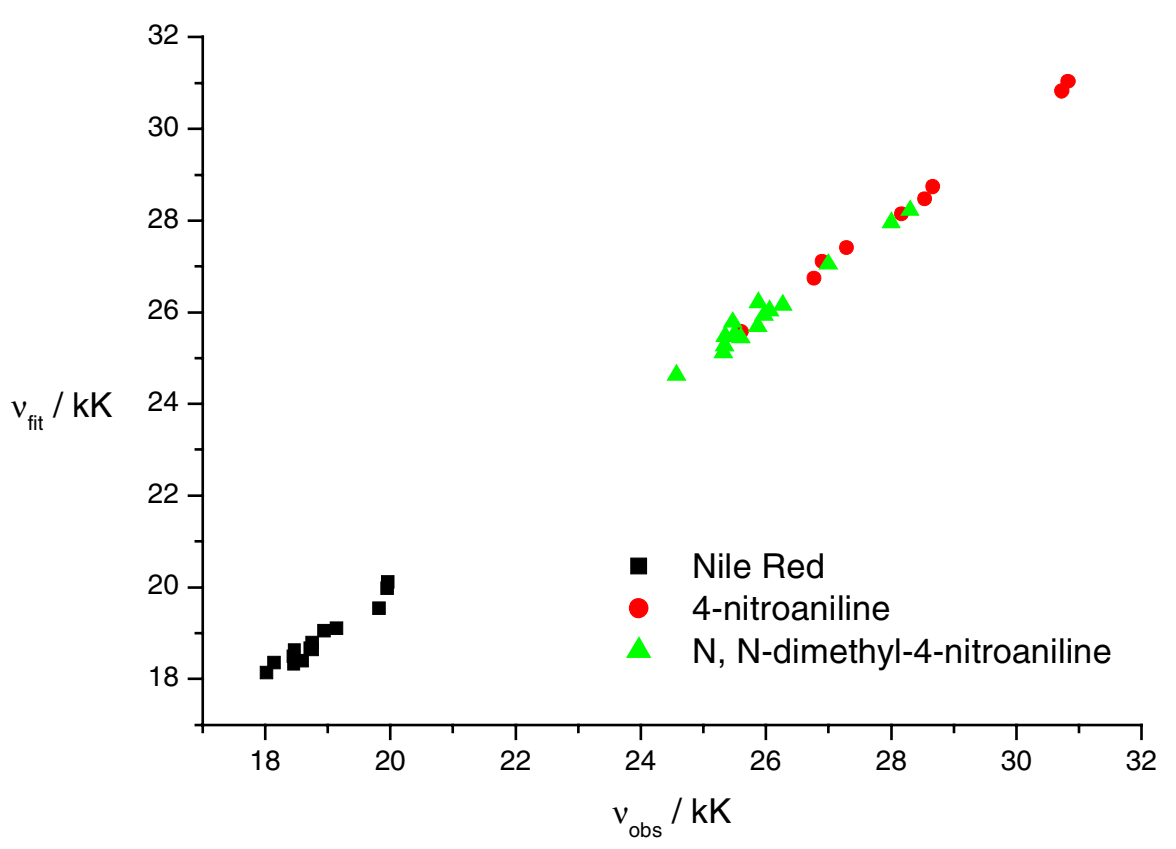


Table 1(supp): absorbance maximum in wavenumbers / $10^{5}(\mathrm{kK})$ with three indicators, Nile red, 4nitroaniline and $\mathrm{N}, \mathrm{N}$-dimethyl-4-nitroaniline in a variety of liquid solvents under ambient conditions. $\left(\alpha, \beta\right.$ and $\pi^{*}$ values from Kamlet, M. J.; Abboud, J-L. M.; Abraham, M. H.; Taft, R. W. J. Org. Chem. 1983, 48, 2877)

\begin{tabular}{|c|c|c|c|c|c|c|c|c|c|}
\hline & v Nile Red & v 4-Nanil & $v \mathrm{~N}, \mathrm{~N}$ di methyl & & & & $v$ Nile Red fit & v 4-Nanil fit & $\begin{array}{l}v \mathrm{~N}, \mathrm{~N} \text { di } \\
\text { methyl fit }\end{array}$ \\
\hline Solvent & $/ \mathrm{kK}$ & / kK & / kK & $\pi^{*}$ & $\alpha$ & $\beta$ & / kK & / kK & $/ \mathrm{kK}$ \\
\hline $1 \mathrm{DCM}$ & 18.6 & 28.67 & 25.32 & 0.802 & 0.3 & 0 & 18.39375 & 28.7348 & 25.11995 \\
\hline 2 Cyclohexane & 19.95 & 30.73 & 28 & 0 & 0 & 0 & 19.978 & 30.82 & 27.956 \\
\hline 3 Toluene & 19.14 & - & 26.27 & 0.54 & 0 & 0.11 & 19.10158 & 29.03276 & 26.15996 \\
\hline $4 \mathrm{DCE}$ & 18.72 & - & 25.34 & 0.807 & 0 & 0 & 18.66824 & 28.7218 & 25.27192 \\
\hline 5 Hexane & 19.96 & 30.83 & 28.3 & -0.081 & 0 & 0 & 20.10946 & 31.0306 & 28.22541 \\
\hline 6 Anisole & 18.75 & 28.17 & 25.5 & 0.734 & 0 & 0.22 & 18.78672 & 28.14512 & 25.51472 \\
\hline 7 Diethylether & 19.82 & 28.54 & 27 & 0.273 & 0 & 0.47 & 19.53492 & 28.47272 & 27.048 \\
\hline 8 Acetonitrile & 18.75 & - & 25.35 & 0.713 & 0.19 & 0.31 & 18.64182 & 27.88616 & 25.47778 \\
\hline 9 THF & 18.94 & 27.29 & 26.06 & 0.576 & 0 & 0.55 & 19.04315 & 27.4062 & 26.04022 \\
\hline 10 DMSO & 18.14 & 25.61 & 24.57 & 1 & 0 & 0.76 & 18.355 & 25.57216 & 24.63 \\
\hline $11 \mathrm{MeOH}$ & 18.02 & 26.9 & 25.6 & 0.6 & 0.93 & 0.62 & 18.12814 & 27.09992 & 25.43774 \\
\hline $12 \mathrm{EtOH}$ & 18.46 & 26.77 & 25.87 & 0.54 & 0.83 & 0.77 & 18.31972 & 26.73332 & 25.6935 \\
\hline 13 iso- $\mathrm{BuOH}$ & 18.29 & - & 25.95 & - & - & - & - & 30.82 & - \\
\hline 14 Prop-2-ol & 18.45 & 26.4 & 25.97 & 0.48 & 0.76 & 0.95 & 18.48304 & 26.2622 & 25.9324 \\
\hline 15 Chloroform & 18.47 & 28.55 & 25.47 & 0.58 & 0.44 & - & 18.62218 & - & 25.77964 \\
\hline $16 \mathrm{t}-\mathrm{BuOH}$ & 18.66 & 26.54 & 25.88 & 0.41 & 0.68 & - & 18.67201 & - & 26.21018 \\
\hline
\end{tabular}

